\title{
On Measuring Child Costs: With Applications to Poor Countries
}

\section{Angus S. Deaton}

Princeton University

\section{John Muellbauer}

Nuffield College

The theoretical basis for measuring child costs is discussed, and detailed consideration is given to two straightforward procedures for calculation, Engel's food share method and Rothbarth's adult good method. Each of these methods embodies different definitions of child costs so that the same empirical evidence can generate quite different estimates depending on the method used. It is shown that true costs are generally overstated by Engel's method and understated by Rothbarth's procedure, although the latter, unlike the former, can provide a sensible starting point for cost measurement. Our estimates from Sri Lankan and Indonesian data suggest that children cost their parents about 30-40 percent of what they spend on themselves.

\section{Introduction and Summary}

This paper is concerned with the measurement of child costs and the associated comparison of welfare levels between households of different sizes. That children impose economic costs on their parents seems

Prepared for the Living Standards Measurement Study, the World Bank, Washington. The views expressed are those of the authors and should not be attributed to the World Bank, to its affiliated organizations, or to any individual acting on their behalf. We should like to thank Jacques van der Gaag, Jim Heckman, Ed Lazear, Bob Michael, Sherwin Rosen, Amartya Sen, Bobby Willig, and an anonymous referee of this Journal for helpful comments. 
to be widely accepted. There is little agreement, however, on the appropriate conceptual basis for the measurement of such costs. This is unfortunate because child costs are a central element in any attempt to make comparisons of standards of living between households of different sizes. In most data, total household expenditure (or income) is positively but less than proportionately related to household size. In consequence, use of household expenditures or incomes as a measure of living standards automatically associates poverty with small household size just as the use of a per capita measure ensures the opposite, an overrepresentation of large households among the poor. See, for example, Kuznets (1979), Visaria (1979), or Lipton (1983a, 1983b) for discussions of actual empirical cases. To actually discover something about the relationship between family size and poverty, as opposed to asserting some relationship, it is necessary to have an agreed-on procedure for defining and measuring the actual costs of children. A similar necessity arises if one attempts to explain fertility itself. Many of the most wisely canvassed theories rely heavily on child costs as the most important price affecting demand (see, e.g., Becker 1960; Becker and Lewis 1973; Becker and Tomes 1976). More broadly, Caldwell (1982) has argued that the demographic transition from high to low fertility is associated with the contrast between economic benefits of children in poor, traditional rural societies and high economic costs of children in rich, westernized industrial societies. The supposition that children bring net economic benefits is also implicit in much of Simon's $(1977,1981)$ writing on fertility and in his view of population as an economic resource.

In Section II we discuss the conceptual basis for measures of child costs and make a comparison of several of the procedures that have been used in the literature. We show how the same evidence on the relationship between household demographic composition and household expenditure patterns can lead to quite different measures of child costs depending on the model used. The reason for this is that different models embody different conceptions of child costs, usually implicitly, so that different models, although each purports to measure the "costs of children," are not in fact measuring the same thing. This situation contrasts with the usual case in empirical work in which model selection, although capable of influencing the results, is not usually the crucial determining factor. For example, given sufficient data and an absence of mistakes, we could reasonably expect two investigators to estimate much the same demand elasticity for food even if they were to choose to work with different functional forms for the Engel curve. But demand elasticities are better defined than are child costs, and the choice of concept is not usually implicitly selected along with the functional form. 
Section III is concerned with two of the simplest and most popular methods of measuring child costs. The first, which we shall refer to as the Rothbarth method, was originally suggested by Erwin Rothbarth (1943), although the method is often associated with the names of the authors of the two earliest empirical studies, Nicholson (1949) and Henderson (1949, 1950a, 1950b). More recent applications of the method are Espenshade (1973) for the United States and Fiegehen, Lansley, and Smith (1977) for the United Kingdom. The second method, even more popular than the first, was suggested by Engel (1895) and has been widely used; see, for example, Deaton (1981) for an application to Sri Lanka and Espenshade (1984) for a very recent use of the method to estimate the costs of children in the United States. These methods are far from being the only procedures for calculating child costs, but they are extremely simple to use, and their assumptions appear to have found wide favor. We show that the two methods make different and mutually incompatible assumptions about the nature of child costs, and we argue that, under mild assumptions, the Engel method will produce estimates that are too large while the Rothbarth method, though perhaps more plausible, is likely to produce estimates that are too small. Under more restrictive assumptions, but ones that may not be unreasonable for families in poor countries, we prove a system of inequalities linking the two measures with more general measures based on Gorman's (1976) extension of the model originally proposed by Barten (1964). In particular, the Barten-Gorman measure of costs lies between the (large) Engel estimate and the (small) Rothbarth estimate. We illustrate the procedures and the inequalities using data from Sri Lanka and Indonesia; under the most extreme assumptions, the Engel method makes children about four times as expensive as does the Rothbarth method. We argue that, with appropriate modification, the Rothbarth procedure is a sensible starting point for the measurement of costs and that the Engel method is based on inherently implausible and indefensible assumptions. For the two countries we use for illustration, our results suggest that child costs are about $30-40$ percent of per capita adult expenditures.

\section{The Conceptual Basis for Measures of Child Costs}

There are two essentially separate literatures on child costs: one familiar to demographers (see, e.g., Lindert $[1978,1980]$ or Espenshade [1972] for references) and one that is rooted in consumer demand analysis (see Deaton and Muellbauer [1980, chap. 8] for many of the references). Although there is some evidence of crossfertilization in the most recent work (e.g., Espenshade 1984), there is 
surprisingly little overlap between the two strands, and few papers are cited in both. Although we believe that the approach followed in much of the demographic literature lacks a rigorous theoretical foundation, it contains a number of important insights that have to some extent been lost sight of in the economics literature. For example, in Dublin and Lotka (1930; 2d ed. 1946), the authors attempt, for actuarial purposes, to estimate the "money value of a man" net of input costs, that is, the costs of bringing the individual to maturity. Dublin and Lotka measure these costs in an apparently straightforward way, beginning appropriately enough with the "costs of being born" (1946, p. 45), estimated in 1946 prices at $\$ 185-\$ 200$ for a typical family of moderate means. A more modern version of the same procedure uses regression analysis to estimate the additional expenditures associated with various classes of children so that simple addition can be used to measure total costs (see Lindert 1978, 1980). While we shall argue that these simple procedures are not appropriate without a clearer idea of the concepts involved, Dublin and Lotka's costs of being born are clearly a legitimate part of any sensible definition of child costs so that this example provides an excellent touchstone for assessing other, more complex methods.

There are immediate practical difficulties with simple schemes that add up the additional costs associated with children. In particular, unless a newborn child comes with an endowment, household resources are the same after the event as they were before it. Additional expenditures associated with the child must therefore be met by adjustments elsewhere, for example, by cutting other current or future expenditures or leisure. In consequence, the sum of all additional outlays, negative and positive, must be zero unless we are given prior information about which (positive) expenditures to count and which (negative) ones to ignore. More fundamentally, the notion of child costs implies a potential compensation that will restore some measure of welfare to its level prior to the existence of the child. If this welfare measure is not made explicit, we cannot tell whether or not any given formula for calculating the compensation makes sense.

The economic approach to child costs makes a better start in this direction if only because it is usually accompanied by writing down a utility function that can be used as the basis for index number or consumer surplus comparisons of situations with different demographics. For example, suppose that the welfare of the parents is given by

$$
u=v(\mathbf{q}, \mathbf{a}) \text {, }
$$

where $\mathbf{q}$ is a vector of household consumption levels and $\mathbf{a}$ is a vector of demographic characteristics, for example, the number of persons 
in each age and sex category. Note the focus on parental utility: the parents are assumed to be the decision makers, and in addition they are the only people who are present both before and after the arrival of the children. For the moment, the arguments of equation (1) require little discussion; the model is consistent with parents' obtaining utility from their children as well as from their own and their children's consumption. Associated with (1) is a cost or expenditure function $c(u, \mathbf{p}, \mathbf{a})$ that gives the minimum expenditure necessary to attain utility $u$ at prices $\mathbf{p}$ and composition a so that, if $u^{R}$ and $\mathbf{p}^{R}$ are some reference utility level and price vector, the additional cost of $\mathbf{a}^{1}$ over $\mathbf{a}^{0}$ is given, as in consumer surplus calculations, by

$$
C=c\left(u^{R}, \mathbf{p}^{R}, \mathbf{a}^{\mathbf{l}}\right)-c\left(u^{R}, \mathbf{p}^{R}, \mathbf{a}^{0}\right) .
$$

Alternatively, an index number methodology can be used, in which case the relative costs are expressed as a ratio, or equivalence scale,

$$
E=\frac{c\left(u^{R}, \mathbf{p}^{R}, \mathbf{a}^{1}\right)}{c\left(u^{R}, \mathbf{p}^{R}, \mathbf{a}^{0}\right)}
$$

Note that, in both measures, utility is held constant across the comparison, though in general both the scale and the cost measure will be functions of both the reference utility level and the price vector.

The parental preferences given by the utility function (1) or the cost function will generate a corresponding system of demand functions that relates observed expenditures on goods to income, prices, and demographic characteristics. Estimation of this system yields information about the preference parameters and thus holds out the hope of identifying the cost or scale measures (2) and (3). However, as first pointed out by Pollak and Wales (1979), knowledge of the system of demand functions for commodities (including, in principle, leisure and saving) is not sufficient to identify the child cost measures. For a similar point in the context of taste and quality change, see Fisher and Shell (1971) and Muellbauer (1975). The problem lies in the treatment of the demographic characteristics as fixed "modifiers" of preferences rather than as choice variables in their own right. In standard index number or consumer surplus theory, costs of two situations are compared with reference to a fixed indifference curve, and the labeling of this indifference curve is of no consequence for the measurement. In other words, monotonic increasing transformations of the utility function affect neither the observable demands nor the calculation of compensations. However, in the current case, any function of $u$ in (1) that also involves the vector of demographics, a, while leaving the observable demand functions unchanged, will generally affect the compensations calculated by (2) or (3). Such transformations relabel indifference curves in a way that depends on the demographic com- 
position of the household so that the presence of an additional child might, for example, make the parents better off without in any way changing their behavior. The obvious possibility is that, when they have children, parents may feel much happier in a way that has nothing to do with their consumption pattern.

Formally, if we define $\theta(u, \mathbf{a})$ as some function that is increasing in its first argument, then the cost function

$$
c[\theta(u, \mathbf{a}), \mathbf{p}, \mathbf{a}]
$$

generates demand functions linking purchases to incomes, prices, and demographics that are unaffected by the choice of function $\theta$. As a consequence, any parameters in the function $\theta$ cannot be recovered from empirical observation of these demand functions, and the cost measures are therefore not identifiable from such observation. To make progress, we must either find some other way of estimating $\theta$ or else construct a procedure that is defensible for any $\theta$ function.

One possible procedure is to treat the demand for children symmetrically with the demand for other goods so that fertility equations are estimated jointly with commodity demand, savings, and labor supply equations. There are obvious problems in measuring appropriate "prices" for children, but if these can be overcome, the problem discussed above no longer exists and index numbers and consumer surplus calculations can be carried out in the standard way. Parents' attitudes toward children are revealed by their fertility behavior, and their trade-offs between goods and children by their joint selection of goods and children in response to changes in prices and incomes. We have doubts whether the economic theory of fertility is sufficiently well developed at an empirical level to make such an exercise feasible, but, more important, we do not believe that such models are appropriate for the concept of child costs that we are trying to measure. If we suppose that most parents are parents because they want to have children, then the compensation that would have to be paid to restore them to their utility level prior to the birth of the child would be negative since they are now better off than they were before. But this is simply not relevant to the problem of measuring the costs of the upkeep of the child, the costs of being born, or the costs of food and education. That parents choose to have children means that the benefits of having them are greater than the costs, but it does not mean that the costs are zero.

What is required is a narrower and more purely economic definition of parental welfare, and one that excludes the benefits of the children themselves, whether real or psychological. For an individual, it is usual to think of economic well-being as directly related to the individual's level of expenditure, as given, for example, by the 
indirect utility function. If it were possible to separate the household accounts into expenditures attributable to adults and children separately, then a measure of the level of living of the adults could be constructed based on the adults' expenditure level. Unfortunately, the data do not come in such a form, and, at a conceptual level, there are formidable difficulties in dealing with shared or household "public goods." It is therefore necessary to define some alternative protocol for measuring the economic welfare of the adults, and all the standard economic methods for measuring child costs do so in one way or another, although not always explicitly. Once done, a procedure is thereby defined whereby it is possible to detect whether welfare is higher or lower in any two real or hypothetical situations so that it is possible to calculate a compensation that will equalize parental welfare before and after a change in household composition, thus establishing its cost. Much of Section III below is concerned with making explicit the welfare definitions implied by the standard procedures, discussing their reasonableness, and drawing out the consequences of using them.

In the rest of this paper we shall confine ourselves to measures of child costs that can be estimated from a single household expenditure survey. This prevents us from discussing issues that arise when prices vary, and some of the more elaborate models of child costs require price variation to identify their parameters. However, one of our main concerns is with schemes that are straightforward to implement and that require only data that are likely to be widely available. The two methods we discuss are really the only serious contenders for such situations, and we believe that much can be learned from studying them. However, these practical limitations limit our analysis to short-run measures of child costs and parental welfare. It would be an important and rewarding exercise to follow households through the life cycle and perhaps to treat children as investment goods, with costs in terms of goods and time (leisure forgone) when the parents and children are young and with a reversal (at least as insurance) when the children are older. It is easy to imagine that the net costs over the life cycle to the parents could be very different from the short-run costs that are inferred from studying household budgets, the costs of being born for those with very young children, or the costs of education that are borne by parents with college-age offspring. Although we confine ourselves to the short-run costs and we make no attempt to allow for time costs, we recognize the existence and importance of the wider concepts as well as the substantial literature that exists on examining the interactions between children, time, and work effort (see, e.g., Gronau 1974; Heckman 1974). We also believe that the general framework laid out above could be straightforwardly adapted to deal with life-cycle considerations. 


\section{Engel and Rothbarth Estimates of Child Costs}

\section{A. Engel}

Engel's (1895) method rests on the supposition that the standard of living of adults is correctly indicated by the share of the household budget devoted to food. Given this, the cost of a newborn child can straightforwardly be measured by calculating the compensation that would have to be paid to the parents to restore the household food share to its prenatal level. We shall give examples of the calculations below, but we first consider the basis for the central identifying assumption, that the adults in two households with different numbers or ages of children are equally well off if the households have the same food share.

The plausibility of the Engel assumption seems to be based on empirical evidence that $(a)$ for households of the same demographic composition, the food share varies inversely with income or total expenditure (Engel's law) and that (b) for households with the same income or total expenditure level, the food share is an increasing function of the number of children. Point $b$ is reasonable enough because additional individuals decrease effective income per individual and because children's needs are likely to be biased toward food compared with those of their parents, particularly in developing countries. However, the acceptance of both $a$ and $b$ does not imply that households with the same food share but different compositions have the same level of welfare. Nicholson (1976) has provided an excellent counterexample. Suppose that the true child costs were known and that a young couple were perfectly compensated for the expenses associated with their newborn child. As a first approximation, we should expect the adults' consumption pattern to be more or less what it was before. However, the household contains a new, largely food-consuming individual. Hence, although fully compensated, the household has a higher food share than before the arrival of the child. Restoration of the food share to its original level would require overcompensation, and this is what the Engel procedure does. This argument seems to us to be quite compelling in spite of the absence of an explicit model of the true compensation. But it can easily be formalized. Write the food share $w_{f}$ as

$$
w_{f}=\sum_{i \in f} \frac{\partial \ln c\left(u, \mathbf{p}^{-\mathbf{z}}\right)}{\partial \ln p_{i}}=\psi(u, \mathbf{p}, \mathbf{a}) .
$$

Then the crucial assumption required for Nicholson's argument is that

$$
\psi\left(u^{0}, \mathbf{p}, \mathbf{a}^{1}\right) \geq \psi\left(u^{0}, \mathbf{p}, \mathbf{a}^{0}\right),
$$


where $\mathbf{a}^{1}$ corresponds to $\mathbf{a}^{0}$ plus an extra child. The inequality asserts that a household that has been fully compensated for the costs of an additional child has a higher food share than it did prior to the child's arrival. It can be derived from a number of more primitive assumptions and rests fundamentally on the share of food in child costs being relatively large and on the presence of the child not causing its parents to consume sufficiently less food to offset the child's own demands. The Engel procedure gives the parents $u^{*}$, defined by

$$
\psi\left(u^{*}, \mathbf{p}, \mathbf{a}^{1}\right)=\psi\left(u^{0}, \mathbf{p}, \mathbf{a}^{0}\right)
$$

so that $\psi\left(u^{*}, \mathbf{p}, \mathbf{a}^{1}\right) \geq \psi\left(u^{0}, \mathbf{p}, \mathbf{a}^{0}\right)$, which, by Engel's law, implies that $u^{*}$ $\geq u^{0}$, that is, that the true scale must be less than or equal to the Engel scale.

Calculation of the Engel measure requires an estimated Engel curve for food. For a two-good disaggregation of the budget into food and nonfood, there is no integrability issue so that any homogeneous food demand equation can be ex post justified by some utility function. One equation that frequently fits the data well is the Working (1943)-Leser (1963) form, in which the food share is a linear function of the logarithm of total outlay. We choose a simple extension of this that incorporates demographic effects, namely,

$$
w_{f}=\alpha-\beta \ln \left(\frac{x}{n}\right)+\sum_{j=1}^{J} \gamma_{j} n_{j}+\epsilon,
$$

where $n_{j}$ is the number of persons in category $j(j=1, \ldots, J), n$ is the total number of people in the household, $x$ is total expenditure, $\epsilon$ is a random error, and $\alpha, \beta$, and $\gamma$ are parameters. For many of the household surveys from the Third World that we have examined, it is the case that the per capita term $\ln (x / n)$ provides a high degree of the explained variation and that, by comparison, the $\gamma$ parameters are typically estimated to be rather small. A similar result is reported for data from the United States by Espenshade (1984). In practice, the fit of the equation is often improved by the inclusion of a term that is quadratic in $\ln (x / n)$. For simplicity of presentation we shall continue to work with (8), although the child costs that we present in tables 1 and 2 below are calculated on the basis of the quadratic regressions.

A full discussion of the application of (8) to the 1969-70 Socioeconomic Survey of Sri Lanka is given in Deaton (1981, essay 1). For the island as a whole, a useful summary regression is

$$
\begin{gathered}
\hat{w}_{f}=1.4330-. .1869 \ln \left(\frac{x}{n}\right)-.0050 n_{a}-.0087 n_{c}, \\
(-90.9)(-8.92)(-16.0) \\
R^{2}=.4864 \text {, E.S.E. }=.0924,
\end{gathered}
$$


where $n_{a}$ and $n_{c}$ are the numbers of adults and children, respectively. The regression uses just under 10,000 observations on the food share, which, in this particular survey, ranges from about 95 percent to less than 20 percent of total outlay. The full regression also contains a number of dummy variables that need not concern us here; quadratic terms are also included and, although not presented here, are significant and are accounted for in the computations of costs. A second example of the Working-Leser food share model is estimated from the Indonesian (Susenas) survey of 1978. Again taking the country as a whole, and this time with just under 6,500 observations, we have

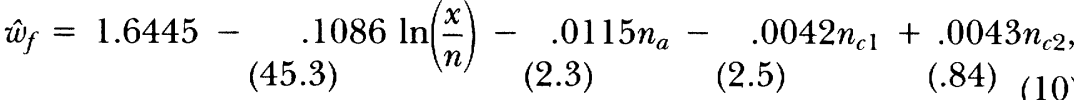

$$
\begin{aligned}
& R^{2}=.2789, \text { E.S.E. }=.1270 .
\end{aligned}
$$

For this survey we distinguish $n_{c 1}$ and $n_{c 2}$, the numbers of small children ( $\leq 5$ years old) and large children ( $>5$ years). As in the Sri Lankan case, the two categories could have been combined without significant loss of fit, but retaining the split is useful for reasons that will appear below. Although we confine ourselves to these two equations, we believe that they are not atypical of food share equations from household surveys in poor countries. In particular, the range of the coefficients on $\ln (x / n)$ shown here, from -.1 to -.2 , covers most of the estimates of which we are aware.

The general procedure for converting Engel curve estimates into child cost measures is illustrated in figure 1 . At some essentially arbitrary food share $w_{f}^{0}, x^{0}$ and $x^{*}$ are the budgets that would cause the reference and large households to have the same food share and thus the same welfare level. The difference $\left(x^{*}-x^{0}\right)$ is the additional expenditure required by the larger household and is thus the measure of child costs. The equivalence scale is simply the ratio $x^{*} / x^{0}$. Note that both the cost measure and the scale will generally be different for different values of $w_{f}^{0}$; this is quite acceptable since costs may well be different at different levels of the budget. For the specific Engel curves given by (8), define $x^{*}$ as the outlay required by household $h$ to reach the same welfare level as the reference $h=0$ with $x^{0}$ and $\mathbf{a}^{0}$. When the food shares are equal, $x^{*}$ is defined by

$$
\alpha-\beta \ln \left(\frac{x^{*}}{n^{h}}\right)+\Sigma \gamma_{j} n_{j}^{h}=\alpha-\beta \ln \left(\frac{x^{0}}{n^{0}}\right)+\Sigma \gamma_{j} n_{j}^{0},
$$

so that, for the Engel equivalence scale $E_{E}^{h}=x^{*} / x^{0}$, we have

$$
E_{E}^{h}=\left(\frac{n^{h}}{n^{0}}\right) \exp \left[\sum_{1}^{J}\left(\frac{\gamma_{j}}{\beta}\right)\left(n_{j}^{h}-n_{j}^{0}\right)\right] .
$$




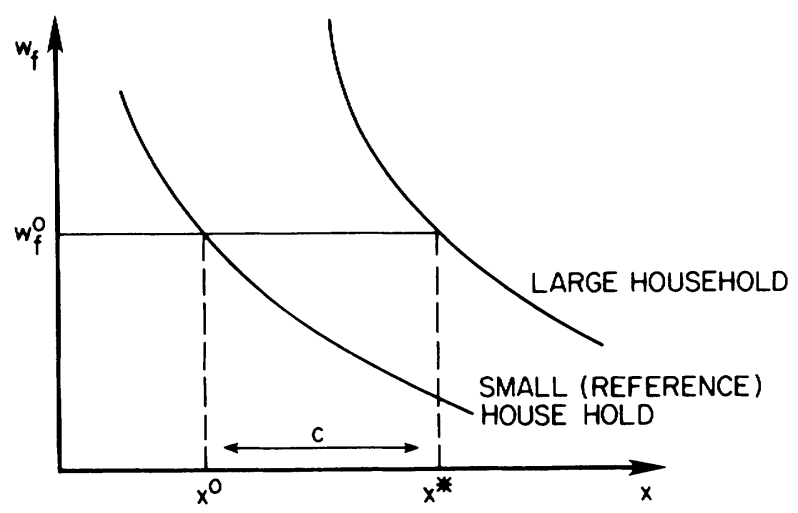

FIG. 1.-Engel's method for child costs

Note that, because in our applications the $\gamma$ 's are small relative to $\beta$, the Engel scale is approximately equal to the head count ratio, $n^{h} / n^{0}$, although, for $\gamma<0, E$ will be less than the ratio (note that $\beta>0$ by Engel's law). If the $\gamma$ 's are estimated to be zero, everyone counts the same, and children are estimated as costing as much as adults.

Table 1 gives the estimated Engel scales using the parameters from the quadratic version of (8) and calculated at the mean of total expenditure. The reference household is one that contains two adults so that the Sri Lankan figures give one child as costing 82 percent of an adult and two children as 77 percent each. The numbers for small children in Indonesia are very similar, but now the large children apparently cost more than an adult. This, of course, is a consequence of the positive coefficient on the large children in (10), and since this is not significantly greater than zero, neither are the estimated child costs significantly greater than the adult costs. But all the figures in the table are implausibly large and would be so even for a developed country, let alone poor countries like Sri Lanka and Indonesia.

These figures undoubtedly depend to some extent on our choice of functional form. However, the results follow from our finding that the food share depends, to a first order of approximation, on per capita income or expenditure, and this finding does not seem to be special to our data or to our functional form. But we also expected the Engel scales to be too large on theoretical grounds. As we argued above, there is no convincing basis for the crucial assumption that the food share correctly indicates adult welfare, and we showed that the use of the assumption will lead to estimates of child costs that are too large. 
TABLE 1

Estimated Engel Equivalence Scales

\begin{tabular}{lcc}
\hline \hline \multirow{2}{*}{\begin{tabular}{l} 
Couple Only \\
\multirow{3}{*}{$\begin{array}{l}\text { With One } \\
\text { Child }\end{array}$}
\end{tabular}} & $\begin{array}{c}\text { With Two } \\
\text { Children }\end{array}$ \\
\cline { 2 - 4 } 1.00 & \multicolumn{3}{c}{ Sri Lanka (1969-70) } \\
\cline { 2 - 4 } & 1.41 & 1.77 \\
\cline { 2 - 4 } 1.00 & \multicolumn{3}{c}{ Indonesia (1978) } \\
\cline { 2 - 4 } 1.00 & $1.45^{*}$ & $1.86^{*}$ \\
\hline
\end{tabular}

* Refers to children 5 years old or younger.

$\dagger$ Refers to children older than 5 years old.

\section{B. Rothbarth}

Rothbarth identified his estimate of child costs by prior selection of a group of adult goods, the total expenditure on which correctly indicates adult welfare. The presence of children is assumed to affect the total expenditure on adult goods only through income-like effects so that, if the correct compensation for child costs were to be paid, expenditure on adult goods would be unaltered by changes in the number of children. Hence, while the Engel method works by calculating the amount of money that would restore the food share to its previous level, the Rothbarth method calculates the sum of money that would restore the level of expenditure on adult goods. Rothbarth himself used a very broad definition of adult goods including virtually all luxury goods as well as saving. Later authors have tended to work with narrow groupings, most popularly with drink and tobacco. As pointed out by Cramer (1969), this can cause problems since neither category seems to be typically very responsive to changes in income so that the income effects required to measure the compensation are hard to establish. For the moment, we postpone the issue and assume that we have a two-way grouping of commodities into adult goods (A goods) and other goods (B goods). Note that it is not assumed that the $\mathrm{B}$ goods are child goods. These are all the goods that are not pure adult goods, and though pure child goods are included, so are goods consumed by both as well as public goods that are jointly consumed.

As is the case for the Engel procedure, the assumption that identifies welfare is an untestable or identifying assumption that allows us to interpret behavior but places no restriction on its form. Of course, if it is assumed that there are many adult goods, all of which are affected by changes in the numbers and ages of children as if by income changes, then the appropriate restrictions can be tested. 
Deaton, Ruiz-Castillo, and Thomas (1985) show how this can be done and obtain reasonably positive results using a Spanish household survey. However, the general proposition that total expenditure on adult goods correctly indicates adult welfare cannot be tested empirically and can only be justified on a priori grounds. As we have already argued, total household expenditure attributable to the adults would be a sensible (and narrow) measure of the adults' standard of living, and one that is in line with the standard economic practice of measuring living standards in terms of real income. The question is then whether the part of this total that is clearly attributable to adults only is itself a sensible measure of welfare. If the parents' preferences are separable between their own consumption and that of their children, there will exist subgroup demand functions that relate the consumption of each adult good to total adult expenditure and to the prices of all goods consumed by the adults (some of which are also consumed by their children). As we shall see below, it can be argued that the presence of children may well alter the effective prices of adult goods, but if this effect is either absent or unimportant, Rothbarth's procedure for indicating the total by one of its parts will be valid, at least if the prespecified adult goods are normal goods.

This argument seems to us to be reasonably convincing and is much more satisfactory than any corresponding justification that can be created for the Engel assumption that the food share indicates adult welfare. Even so, the supposition that children do not alter relative prices can be challenged in terms of Barten's (1964) or Gorman's (1976) model of demographic effects (see also Pollak and Wales 1981). In these, the presence of children makes goods that are shared with children relatively more expensive than pure adult goods-"a penny bun costs three pence when you have a wife and child"- -so that there may be substitution toward adult goods in households with children. It is far from established that the effects of children work this way (see, e.g., Muellbauer 1977), but if they do, the Rothbarth measure of costs will be too small. A household that is perfectly compensated for the costs associated with the arrival of a child will display greater consumption of pure adult goods than before the event. The Rothbarth procedure will pay compensation only to the point where consumption of pure adult goods is unchanged, which is not enough. These arguments suggest that the Rothbarth method should be used with circumspection when the presence of children is likely to cause substitution toward what appears to be a purely adult good. For example, children rarely listen to recordings of Bartok string quartets, but the parents might be induced to increase this activity by the presence of children, either for its soothing effects or because it is now 
more difficult and expensive to attend live concerts. Other examples can readily be imagined.

The Rothbarth procedure is applied in very much the same way as the Engel procedure. An Engel curve is established for the total of adult goods, and its slope is used to calculate the income that would be required to nullify the negative effects of additional children on the total. Note that children need not be homogeneous but can readily be distinguished by sex and age. Indeed, the Rothbarth model would seem to be a good candidate to use in the investigation of "sex bias" in family consumption (see Sen [1984] for some evidence). If parents treat female children less generously, the presence of female children should have less effect on adult consumption than the presence of their male siblings.

Finally, we note that in a recent paper, Gronau (1985), while endorsing the Rothbarth model in principle, has pointed out that, if parents derive utility from the consumption of their offspring, their marginal propensities to spend on purely adult goods are likely to be reduced by the presence of additional children. If the Engel curve slopes are affected in this way and if the phenomenon is ignored, then the calculated Rothbarth costs will be too small since, with a reduced propensity to spend, larger compensations must be paid to restore any given level of adult expenditure.

\section{Engel versus Rothbarth}

We have argued that the Engel measure of child costs is likely to be too large and the Rothbarth measure too small. Indeed, with some further assumptions, it is possible to prove inequalities between them. In particular, we examine the consequences of applying the Rothbarth procedure under the assumption that all nonfood is an adult good. This is an extreme assumption made in order to allow us to obtain sharp results; it may also be a reasonable approximation for very poor families.

The following is true: if $(a)$ the B goods (nonadult goods) in the Rothbarth model correspond to food in the Engel model and $(b)$ the B goods (i.e., foods) are necessities, then the Rothbarth scale is no larger than the Engel scale. Note that the same empirical evidence is used for both calculations; the inconsistency between the estimates is entirely due to assumption and not to measurement. The argument is straightforward. If, when a child is born, the parents are compensated according to Rothbarth, their nonfood expenditure is unchanged after the child's arrival. But their total expenditure has increased; hence the share of nonfood has risen. Hence, according to 
Engel, they have been undercompensated. The Engel compensation would be more generous and the Engel scale larger. Formally, let expenditure on food be given by the function $g(x, \mathbf{p}, \mathbf{a})$. Then the Rothbarth compensation $x^{* *}$ is defined by

$$
x^{* *}-g\left(x^{* *}, \mathbf{p}, \mathbf{a}\right)=x^{0}-g\left(x^{0}, \mathbf{p}, \mathbf{a}^{0}\right) .
$$

Since $x^{* *} \geq x^{0}$, dividing the left-hand side by $x^{* *}$ and the right-hand side by $x^{0}$ gives

$$
\frac{g\left(x^{* *}, \mathbf{p}, \mathbf{a}\right)}{x^{* *}} \geq \frac{g\left(x^{0}, \mathbf{p}, \mathbf{a}^{0}\right)}{x^{0}} .
$$

But the Engel compensation $x^{*}$ is defined by setting $g\left(x^{*}, \mathbf{p}, \mathbf{a}\right) / x^{*}$ equal to the original share $g\left(x^{0}, \mathbf{p}, \mathbf{a}\right) / x^{0}$. Hence

$$
\frac{g\left(x^{* *}, \mathbf{p}, \mathbf{a}^{0}\right)}{x^{* *}} \geq \frac{g\left(x^{*}, \mathbf{p}, \mathbf{a}\right)}{x^{*}},
$$

which, since $g / x$ is a declining function of $x$ by the necessity assumption, yields

$$
x^{* *} \leq x^{*}
$$

Finally, we illustrate the argument in figure 2, which was provided for us by a referee. Commodity $q_{1}$ on the horizontal axis is food, and the two expansion curves $H$ and $O$ show the combinations of food and nonfood purchased at various total expenditure levels by the reference household $O$ and the larger household $H$. If the initial position is $S, x$ must be increased to $x_{R}$ for the larger household to reestablish the base level of nonfood $q_{2}$, while to reach the same share pattern as $O$, that is, along the ray $O S$, total outlays must be increased to $x_{E}$.

Although the identification of nonadult goods with food is clearly extreme, it is clear that the assumption is not necessary for the result. In particular, the crucial step in the argument is inequality (14), that the food share be larger after Rothbarth compensation has been paid, and it is likely that this will be true for most plausible definitions of adult goods.

Under the assumption that nonfood is the adult good, we have calculated the Rothbarth scales using the estimated Engel curves for Sri Lanka and Indonesia that were given in Section IIIB, again with the quadratic terms added. The food Engel curve (8) does not yield a closed-form solution for the amount that equates nonfood expenditures, but numerical solutions are readily obtained. Representative values are given in table 2 in the same format as table 1 . According to these figures, children cost about one-quarter of an adult, and, once again, the figures are consistent between the two countries. Clearly, 


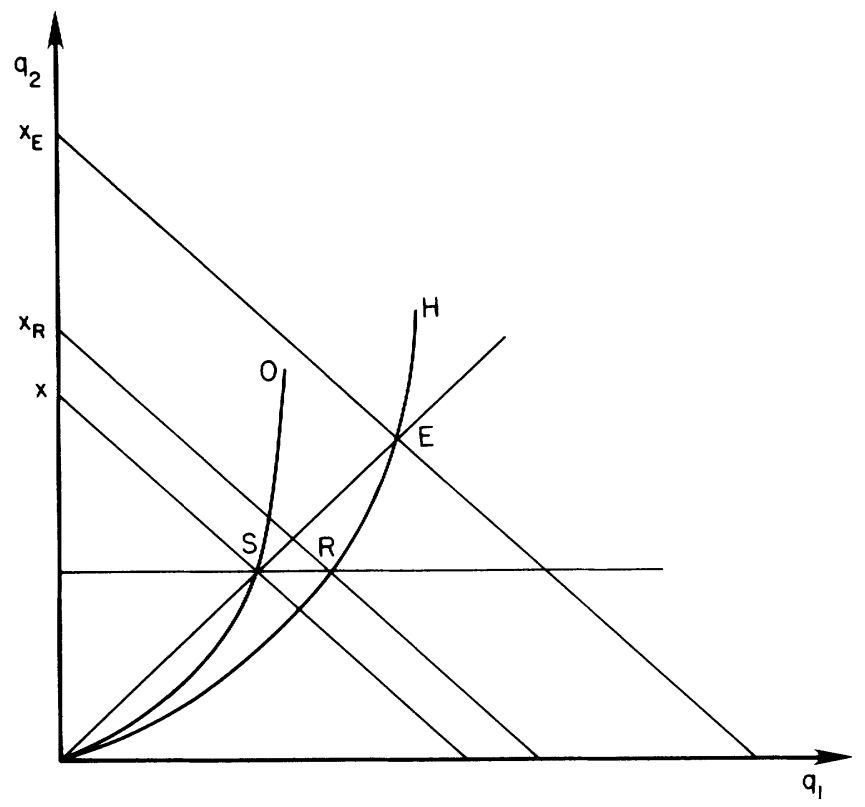

FIG. 2.-Engel vs. Rothbarth compensation

for these examples, the differences between the Engel and Rothbarth procedures are very large.

\section{Engel, Rothbarth, Barten, and Gorman}

If we are to make more precise statements about the strengths and weaknesses of the Engel and Rothbarth approaches, it is necessary to have an alternative, more general model that serves to categorize precisely what happens when there is a failure in the assumptions of the simpler approaches. In this subsection we use Gorman's (1976) generalization of Barten's (1964) model. The Gorman-Barten model is much richer than either the Engel or Rothbarth model and can be regarded as generalizing both of them, so that it is a good candidate for a "true" model against which to evaluate the alternatives.

Barten (1964) writes the utility function associated with the vector of demographics $\mathbf{a}$ in the form

$$
u=v\left[\frac{q_{1}}{m_{1}(\mathbf{a})}, \frac{q_{2}}{m_{2}(\mathbf{a})}, \ldots, \frac{q_{n}}{m_{n}(\mathbf{a})}\right] .
$$

It is possible to interpret this formulation in a number of ways. For our purposes, the most attractive is to regard $u$ as a measure of the parents' standard of living so that $q_{i} / m_{i}(\mathbf{a})$ is the consumption of $\operatorname{good} i$ 
TABLE 2

Estimated Rothbarth Equivalence Scales

\begin{tabular}{lcc}
\hline \hline Couple Only & \multicolumn{1}{c}{$\begin{array}{l}\text { With One } \\
\text { Child }\end{array}$} & $\begin{array}{c}\text { With Two } \\
\text { Children }\end{array}$ \\
\hline \multirow{3}{*}{1.00} & \multicolumn{3}{c}{ Sri Lanka (1969-70) } \\
\cline { 2 - 4 } & \multicolumn{3}{c}{1.21} \\
\cline { 2 - 4 } 1.00 & \multicolumn{3}{c}{ Indonesia (1978) } \\
\cline { 2 - 4 } 1.00 & $1.10^{*}$ & $1.16^{*}$ \\
\hline
\end{tabular}

* Refers to children 5 years old or younger.

† Refers to children older than 5 years old.

that actually reaches the parents when an amount $q_{i}$ is purchased for the family as a whole. The quantity $m_{i}(\mathbf{a})$ is therefore unity if children do not consume the good, it would be two if children get the same as adults, and so on. Note that this interpretation differs from the usual one in which (16) is taken as a representation of household preferences. But such an interpretation makes little sense if we are to use a common welfare level to compare situations with and without children, and this is the whole purpose of the current exercise.

The cost function associated with the Barten model is easily derived by recognizing that the model essentially treats the quantities $q_{i}^{*}=$ $q_{i} / m_{i}(\mathbf{a})$ as the objects of utility with effective "prices" $p_{i}^{*}=p_{i} m_{i}(\mathbf{a})$. The cost function and demand functions can then be written as

$$
\begin{gathered}
x=c\left[u, p_{1} m_{1}(\mathbf{a}), p_{2} m_{2}(\mathbf{a}), \ldots, p_{n} m_{n}(\mathbf{a})\right], \\
q_{i}=m_{i} h_{i}\left[u, p_{1} m_{1}(\mathbf{a}), p_{2} m_{2}(\mathbf{a}), \ldots, p_{n} m_{n}(\mathbf{a})\right] .
\end{gathered}
$$

The important features of (17) and (18) are (a) the scaling up of the reference demands by $m_{i}$ corresponding to the "needs" effects of the additional children and $(b)$ the substitution effects on demand that occur when the presence of children alters the effective prices of parental consumption. Although the model is substantially more general than any so far considered (indeed, as Muellbauer [1977] has shown, if the $m$ 's are the same for all goods, the Engel procedure will be correct), there are important types of behavior that it cannot accommodate. In particular, if the reference household does not consume the good, neither will the household with children except through the operation of substitution effects. Childless households do not use diapers or baby foods while households with small children do. This is not consistent with the Barten formulation except under extremely farfetched assumptions about substitution. Gorman's 
(1976) modification solves this problem by adding fixed costs of children to the Barten cost function. Hence, the Gorman-Barten model has the cost function

$$
x=c\left[u, p_{1} m_{1}(\mathbf{a}), p_{2} m_{2}(\mathbf{a}), \ldots, p_{n} m_{n}(\mathbf{a})\right]+\Sigma p_{j} n_{j}(\mathbf{a}),
$$

where the $n$ 's are fixed costs associated with the demographic vector $\mathbf{a}$. For the reference household, without children, all $n$ 's are zero just as all $m$ 's are unity. Note that, with all $m$ 's unity but nonzero $n$ 's, the Rothbarth procedure is correct provided that goods with zero $n$ 's are taken to be the pure adult goods.

Consider the application of the Rothbarth and Engel procedures to a two-good food/nonfood model when the Gorman-Barten model is in fact correct. Let good 1 be food and good 2 be nonfood, with the latter (falsely) taken to be the adult good in the Rothbarth procedure. To get sharp results, we make some plausible assumptions: (i) $m_{1} \geq 1$, $m_{2} \geq 1$, and $m_{1} / m_{2} \geq 1$; that is, children consume both goods but have a relatively heavy food requirement. (ii) Good 1 is a necessity, and its compensated own-price elasticity is less than unity in absolute value. (iii) For any utility level $u$ and prices $p_{1}$ and $p_{2}$ the effect of more children on the fixed costs $n_{1}$ and $n_{2}$ is to increase the food share. We state this more precisely later but note that the assumption will be satisfied if $n_{1}>0$ and $n_{2}=0$.

We write the derivatives of the first term on the right-hand side of (19) as $m_{i}(\mathbf{a}) h_{i}\left[u, p_{1} m_{1}(\mathbf{a}), p_{2} m_{2}(\mathbf{a})\right]$, for $i=1,2$, so that the demand functions are written as

$$
q_{i}=n_{i}(\mathbf{a})+m_{i}(\mathbf{a}) h_{i}\left[u, p_{1} m_{1}(\mathbf{a}), p_{2} m_{2}(\mathbf{a})\right] .
$$

The budget shares of each commodity can be derived from (20), and we shall use the notation $\sigma_{1}\left(u, p_{1}, p_{2}, n_{1}, n_{2}\right)$ for the food share at prices $p_{1}$ and $p_{2}$ and fixed costs $n_{1}$ and $n_{2}$. Assumption iii above can be restated to say that, if $\mathbf{a}^{1}$ differs from $\mathbf{a}^{0}$ in having more children, then we must have

$$
\sigma_{1}\left[u, p_{1}, p_{2}, n_{1}\left(\mathbf{a}^{1}\right), n_{2}\left(\mathbf{a}^{1}\right)\right] \geq \sigma_{1}\left[u, p_{1}, p_{2}, n_{1}\left(\mathbf{a}^{0}\right), n_{2}\left(\mathbf{a}^{0}\right)\right] .
$$

In other words, children are relatively food intensive in the fixed costs, $n$, as well as in the "scaling" coefficients $m$.

Given the three assumptions, it is now straightforward to show that the true equivalence scale, $E$, say, lies between the Rothbarth and Engel scales. Consider first the case in which the Engel compensation is paid for a change from $\mathbf{a}^{0}$, the reference demographic vector, to $a^{1}$, where $\mathbf{a}^{1}$ contains more children than $\mathbf{a}^{0}$ does. Let the reference utility level be $u^{0}$ and the utility level of $h$ after receiving the payment be $u^{E}$. We show that $u^{E}$ is greater than $u^{0}$, that is, that the household has been 
overcompensated. By the definition of the Engel procedure, $u^{E}$ is defined by

$$
\sigma_{1}\left[u^{E}, m_{1} p_{1}, m_{2} p_{2}, n_{1}\left(\mathbf{a}^{1}\right), n_{2}\left(\mathbf{a}^{1}\right)\right]=\sigma_{1}\left(u^{0}, p_{1}, p_{2}, 0,0\right)
$$

since for the reference household the $m$ 's are unity and the $n$ 's zero. But by assumption iii,

$$
\sigma_{1}\left[u^{E}, m_{1} p_{1}, m_{2} p_{2}, n_{1}\left(\mathbf{a}^{1}\right), n_{2}\left(\mathbf{a}^{1}\right)\right] \geq \sigma_{1}\left(u^{E}, m_{1} p_{1}, m_{2} p_{2}, 0,0\right) \text {. }
$$

The share functions are homogeneous of degree zero in the prices so that the right-hand side of (23) can be written as

$$
\begin{aligned}
\sigma_{1}\left(u^{E}, m_{1} p_{1}, m_{2} p_{2}, 0,0\right) & =\sigma_{1}\left[u^{E},\left(\frac{m_{1}}{m_{2}}\right) p_{1}, p_{2}, 0,0\right] \\
& \geq \sigma_{1}\left(u^{E}, p_{1}, p_{2}, 0,0\right),
\end{aligned}
$$

where the last inequality depends on $\left(m_{1} / m_{2}\right) \geq 1$ by assumption $\mathrm{i}$ and on the price inelasticity of food demand, assumption ii. Combining (22), (23), and (25) and following the chain of inequalities gives

$$
\sigma_{1}\left(u^{0}, p_{1}, p_{2}, 0,0\right) \geq \sigma_{1}\left(u^{E}, p_{1}, p_{2}, 0,0\right) .
$$

By Engel's law, assumption ii, this inequality implies that $u^{0}$ is less than $u^{E}$ so that the Engel procedure overcompensates.

The argument that the Rothbarth procedure undercompensates the Gorman-Barten procedure is more straightforward and requires fewer assumptions; in particular, assumption iii can be replaced by the much weaker one that $n_{2} \geq 0$. If the post-Rothbarth compensation utility level is $u^{R}$, we have

$$
m_{2} h_{2}\left(u^{R}, p_{1} m_{1}, p_{2} m_{2}\right)+n_{2}=h_{2}\left(u^{0}, p_{1}, p_{2}\right) .
$$

But since $m_{1} / m_{2} \geq 1$ and the effective relative price of food is higher for the larger family, we have

$$
\begin{aligned}
m_{2} h_{2}\left(u^{R}, p_{1} m_{1}, p_{2} m_{2}\right) & \geq m_{2} h_{2}\left(u^{R}, p_{1}, p_{2}\right) \\
& \geq h_{2}\left(u^{R}, p_{1}, p_{2}\right)
\end{aligned}
$$

since $m_{2} \geq 1$. Hence, comparing (27) and (29), we have

$$
h_{2}\left(u^{0}, p_{1}, p_{2}\right) \geq h_{2}\left(u^{R}, p_{1}, p_{2}\right)+n_{2} \text {. }
$$

Since $n_{2} \geq 0$ by assumption and since good 2 is normal by Engel's law, (30) establishes that $u^{0} \geq u^{R}$, that is, that the Rothbarth procedure is insufficiently generous.

Figure 3 illustrates both points for the case of $m_{1}=m, m_{2}=1, n_{1}=$ $n$, and $n_{2}=0$. The vertical axis, as before, is $q_{2}$, the adult good, while the horizontal axis is "effective" food consumption $q_{1}^{*}=\left(q_{1}-n\right) / m$. 


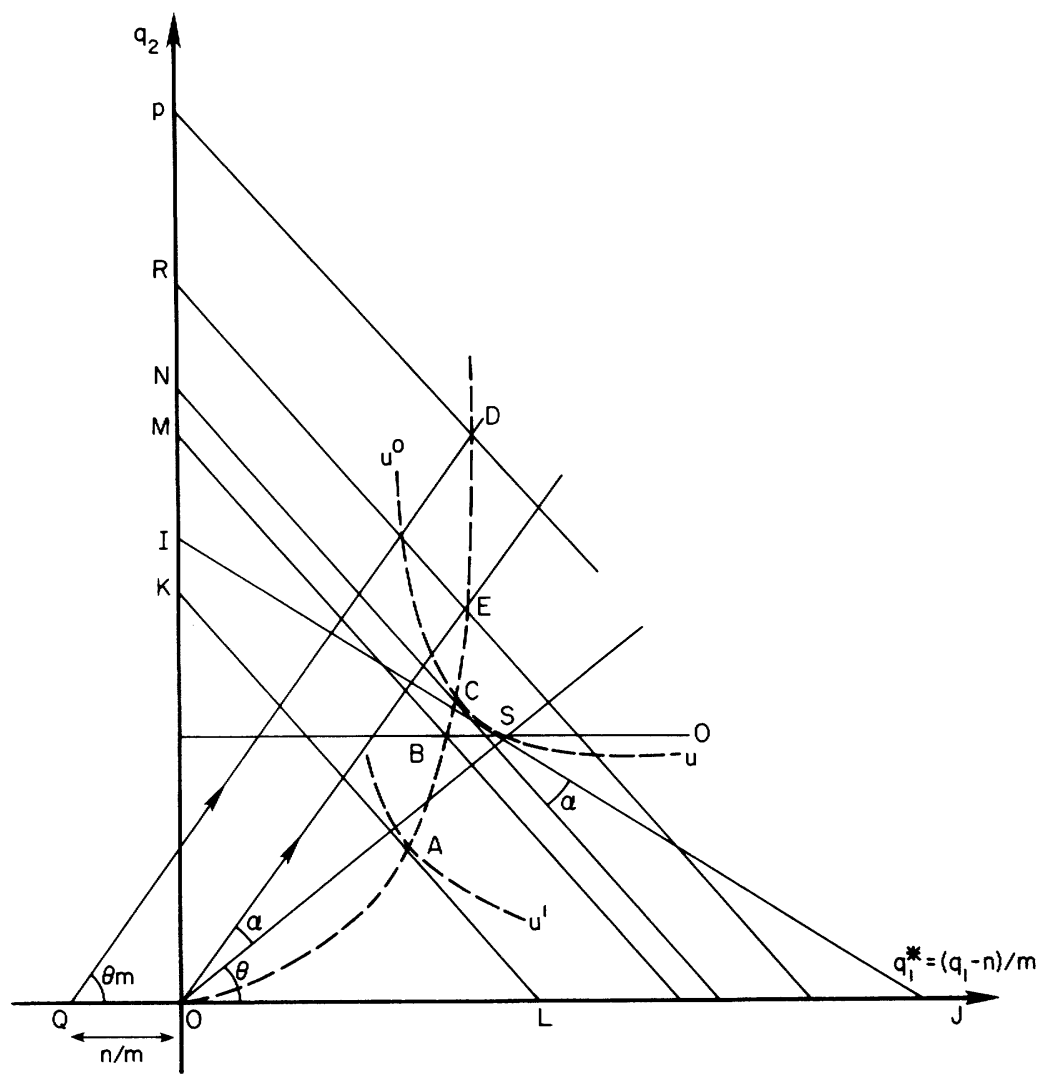

Fig. 3.-Gorman-Barten, Rothbarth, and Engel compensation

The budget line $I J$ is the constraint for the reference household, with the original position at $S$ on the indifference curve $u^{0}$. The additional child has two effects: (i) good 1 becomes relatively more expensive, rotating the budget line through an angle $\alpha$, and (ii) the budget constraint shifts inward because of the fixed cost element for the first good. Line $K L$ is the new position, with choice at $A$ on $u^{1}$. The curve $O A B C D$ is the expansion curve and is convex by Engel's law. If we follow it upward, point $B$ restores the consumption of good 2 to its original level so that $K M$ is the Rothbarth compensation. At $C$, the original indifference curve is reached, so that $K N$ is the true GormanBarten compensation. Clearly $K N>K M$. The Engel compensation is calculated by restoring the original ratio of (uncorrected) $q_{2}$ to $q_{1}$. Let this ratio be $\theta$ so that, if $n=0$ (i.e., the pure Barten case), the Engel compensation is calculated by finding the point at which the ray through $O$ with slope $m \theta$ cuts the expansion curve $O A B C D$ (i.e., at point $E$ ) so that compensation is $K R$. Note that the angle $\alpha$, the differ- 
ence between $\theta$ and $\theta m$, is the same as the difference in slopes between the original and new budget lines $I J$ and $K L$. When $n$ is positive, the food share is restored to its original value along the line $Q D$, with compensation equal to $K P$, which is larger than $K R$ (the Engel compensation when the Barten model is true), $K N$ (the true GormanBarten compensation), and $K M$ (the Rothbarth compensation). The compensation ordering depends on the limited substitution in the original indifference curve so that, in particular, the angle $S O E$ is less than $\alpha$.

\section{Summary, Conclusions, and Recommendations}

In the previous section we discussed in some detail the foundations of two leading methods for calculating child costs, and we compared them with a much more general model. We argued that the Engel model is likely to overstate child costs and the Rothbarth model to understate them. Indeed, if the true technology of child costs can be represented by Barten's model as modified by Gorman, then, under plausible assumptions, the correct measure can be shown to lie between the Rothbarth and Engel measures. In practical applications, however, it will always be extremely difficult to estimate the parameters of the Gorman-Barten model, and the Rothbarth and Engel methods are likely to have continued popularity, if only on computational grounds. It is therefore important to try to assess which, if either, is likely to give a satisfactory approximation.

From the discussion in Section III $D$, it is easily checked that the following are true: (a) The Rothbarth model gives the correct answer if (i) $n_{2}=0$ and $m_{2}=1$ so that there are no fixed costs for the adult (nonfood) good, and (ii) children exert no pricelike substitution effects between the two goods. Condition ii requires either that the Barten-type effects be absent altogether (i.e., $m_{1}=1$ ) or that there be a zero elasticity of substitution between adult and child goods. (b) If there are no fixed costs, the Engel method will give the correct answer if either $m_{1}=m_{2}$, so that there are no child-induced substitution effects, or the compensated price elasticity for good 1 (food) is (minus) unity. With $m_{1} / m_{2}>1$ and with the demand for food price inelastic, the Engel method can be correct only if the fixed child costs for good 2 are larger than those for good 1.

The conditions in $b$ make little sense, and none of them is likely to be satisfied. Conditions $a$ are more plausible, at least in certain contexts. In particular, for poor households close to subsistence, the compensated price elasticity of food as a whole is likely to be very close to zero. The condition that there be no child fixed costs or scaling factors for the adult good simply requires that the adult good be correctly 
identified as such. However, in our food/nonfood applications above, there are presumably some child requirements for nonfood items, for example, clothing. Nevertheless, it may be possible to deal with this by a correction to the Rothbarth scale if the latter is not too far out. Equation (27) gives the relationship between the original utility level and that after compensation according to Rothbarth. If the left-hand side of this is expanded around the point $u=u^{0}, m_{1}=m_{2}=1$, utilities replaced by their income equivalents, and use made of the homogeneity property of substitution elasticities (i.e., that $p_{1} h_{12}+$ $p_{2} h_{22}=0$, where $h_{i j}$ is the derivative of the demand for $i$ with respect to the price of $j$ ), then we obtain

$$
E \simeq E_{R}+\frac{m_{2}-1}{e_{2}}+\frac{n_{2}}{q_{2} e_{2}}+\frac{e_{22}}{e_{2}}\left(m_{2}-m_{1}\right),
$$

where $e_{2}$ is the total expenditure elasticity of good $2, e_{22}$ is its compensated price elasticity, $E$ is the true scale, and $E_{R}$ is the Rothbarth scale. As argued, we can assume the price elasticity to be very small for consumers close to subsistence. The expenditure elasticity can be directly estimated and is typically around two for the surveys used above. The expression $m_{2}-1+\left(n_{2} / q_{2}\right)$ is the amount of nonfood that is "diverted" from adult to child use. If we take a generous view, we might assume that each child gets half as much of good 2 as he would were he an adult. This would mean that one child with two parents would account for one-fifth of nonfood expenditure, and two children with two parents would account for one-quarter. The corresponding corrections to the Rothbarth scales would then be .10 and .125. Applying these to table 2 would suggest that child costs are 30 40 percent of expenditure per adult, figures that seem to us to be both appropriate and defensible.

Note too that these are estimates for Sri Lanka and Indonesia or for countries at similar levels of development, and such corrections to food-based measures would not be appropriate for developed countries where children bring heavy nonfood expenditures. We have also made no allowance for the consequences of children on adult leisure, and though such effects are probably quite limited in poor countries, they are likely to be of major significance in countries such as the United States. However, our conclusion that the Engel method is not well based applies in general, and the Rothbarth method with corrections for substitution effects is much to be preferred in any context. We can construct no plausible defense for the belief that the food share correctly indicates welfare between households of different size, and we do not believe that credence should be given to estimates based on that belief.

We conclude with a warning about the possible misuse of the sort of 
measures we have calculated in this paper. One major use of equivalence scales is to make comparisons of welfare between households of different sizes. But ultimately, welfare comparisons must be based on the welfare levels of individuals, not of households. The measures in this paper tell us about the effects of children on adult welfare, but they do not tell us about the welfare levels of the children themselves. Indeed, we doubt that household expenditure data in anything like their traditional form can tell us very much about the relative welfare levels of adults and children. One possible assumption is that everyone in the household shares the same welfare level, and this would enable comparisons of welfare or inequality with individuals as the basis of analysis. However, there are cases in which such an assumption would be clearly inappropriate, for example, in societies in which women and children are treated as the chattels of a dominant male. In such a society, it might be argued that only adults or only males should count in analyzing welfare. We cannot resolve such issues here, and we are concerned only to point out that the results given above do not attempt to do so.

\section{References}

Barten, Anton P. "Family Composition, Prices and Expenditure Patterns." In Econometric Analysis for National Economic Planning, edited by P. E. Hart, G. Mills, and J. K. Whitaker. London: Butterworths, 1964.

Becker, Gary S. "An Economic Analysis of Fertility." In Demographic and Economic Change in Developed Countries. Princeton, N.J.: Princeton Univ. Press (for N.B.E.R.), 1960.

$\rightarrow$ Becker, Gary S., and Lewis, H. Gregg. "On the Interaction between the Quantity and Quality of Children." J.P.E. 81, no. 2, pt. 2 (March/April 1973): S279-S288.

$\rightarrow$ Becker, Gary S., and Tomes, Nigel. "Child Endowments and the Quantity and Quality of Children.” J.P.E. 84, no. 4, pt. 2 (August 1976): S143-S162.

Caldwell, John C. Theory of Fertility Decline. London: Academic Press, 1982.

Cramer, Jan S. Empirical Econometrics. Amsterdam: North-Holland, 1969.

Deaton, Angus S. "Three Essays on a Sri Lankan Household Survey." Living Standards Measurement Study Working Paper no. 11. Washington: World Bank, 1981.

Deaton, Angus S., and Muellbauer, John. Economics and Consumer Behavior. New York: Cambridge Univ. Press, 1980.

Deaton, Angus S.; Ruiz-Castillo, Javier; and Thomas, Duncan. "The Influence of Household Composition on Household Expenditure Patterns: Theory and Spanish Evidence." Manuscript. Princeton, N.J.: Princeton Univ., Woodrow Wilson School, 1985.

Dublin, Louis I., and Lotka, Alfred J. The Money Value of a Man. New York: Ronald Press, 1930. 2d ed., 1946.

Engel, Ernst, "Die Lebenkosten Belgischer Arbeiter-Familien Fruher und Jetzt.” Internat. Statis. Inst. Bull. 9, no. 1 (1895): 1-74.

$\rightarrow$ Espenshade, Thomas J. "The Price of Children and Socio-economic Theories of Fertility." Population Studies 26 (July 1972): 207-21. 
The Cost of Children in Urban United States. Population Monograph Series no. 14. Berkeley: Univ. California, Inst. Internat. Studies, 1973.

- Investing in Children: New Estimates of Parental Expenditure. Washington: Urban Inst. Press, 1984.

Fiegehen, Guy C.; Lansley, P. Stewart; and Smith, Anthony D. Poverty and Progress in Britain, 1953-73: A Statistical Study of Low Income Households. Cambridge: Cambridge Univ. Press, 1977.

Fisher, Franklin M., and Shell, Karl. "Taste and Quality Change in the Pure Theory of the True Cost of Living Index." In Price Indexes and Quality Change: Studies in New Methods of Measurement, edited by Zvi Griliches. Cambridge, Mass.: Harvard Univ. Press, 1971.

Gorman, William M. "Tricks with Utility Functions." In Essays in Economic Analysis, edited by M. Artis and A. R. Nobay. Cambridge: Cambridge Univ. Press, 1976.

Gronau, Reuben. "The Effect of Children on the Housewife's Value of Time." In Economics of the Family: Marriage, Children, and Human Capital, edited by Theodore W. Schultz. Chicago: Univ. Chicago Press (for N.B.E.R.), 1974.

- "The Allocation of Goods within the Household and Estimation of Adult Equivalence Scales: How to Separate the Men from the Boys." Manuscript. Jerusalem: Hebrew Univ., Dept. Econ., 1985.

$\rightarrow$ Heckman, James J. "Effects of Child-Care Programs on Women's Work Effort." J.P.E. 82, no. 2, pt. 2 (March/April 1974): S136-S163.

Henderson, Alexander M. "The Costs of Children, Part I." Population Studies 3 (September 1949): 130-50.

—_. "The Cost of a Family." Rev. Econ. Studies 17, no. 2 (1950): 127-48. (a)

" "The Costs of Children, Parts II, III." Population Studies 4 (December 1950): 267-98. (b)

Kuznets, Simon. Growth, Population, and Income Distribution: Selected Essays. New York: Norton, 1979.

Leser, Conrad E. V. "Forms of Engel Functions." Econometrica 31 (October 1963): 694-703.

Lindert, Peter H. Fertility and Scarcity in America. Princeton, N.J.: Princeton Univ. Press, 1978.

- "Child Costs and Economic Development." In Population and Economic Change in Developing Countries, edited by Richard A. Easterlin. Chicago: Univ. Chicago Press (for N.B.E.R.), 1980.

Lipton, Michael. "Labor and Poverty." Staff Working Paper no. 616. Washington: World Bank, 1983. (a)

. "Poverty, Undernutrition, and Hunger." Staff Working Paper no. 597. Washington: World Bank, 1983. (b)

Muellbauer, John. "The Cost of Living and Taste and Quality Change." $J$. Econ. Theory 10 (June 1975): 269-83.

- "Testing the Barten Model of Household Composition Effects and the Cost of Children." Econ. J. 87 (September 1977): 460-87.

$\rightarrow$ Nicholson, J. Leonard. "Variations in Working Class Family Expenditure." $J$. Royal Statis. Soc., ser. A 112, pt. 4 (1949): 359-411.

- "Appraisal of Different Methods of Estimating Equivalence Scales and Their Results." Rev. Income and Wealth 22 (March 1976): 1-11.

Pollak, Robert A., and Wales, Terence J. "Welfare Comparisons and Equivalent Scales.” A.E.R. Papers and Proc. 69 (May 1979): 216-21.

. "Demographic Variables in Demand Analysis." Econometrica 49 (November 1981): 1533-51. 
Rothbarth, Erwin. "Note on a Method of Determining Equivalent Income for Families of Different Composition." App. 4 in War-Time Pattern of Saving and Spending, by Charles Madge. Cambridge: Cambridge Univ. Press (for Nat. Inst. Econ. and Soc. Res.), 1943.

Sen, Amartya K. "Family and Food: Sex Bias in Poverty." In Resources, Values, and Development, by Amartya K. Sen. Cambridge, Mass.: Harvard Univ. Press, 1984.

Simon, Julian L. The Economics of Population Growth. Princeton, N.J.: Princeton Univ. Press, 1977.

The Ultimate Resource. Princeton, N.J.: Princeton Univ. Press, 1981.

Visaria, Pravin. "Demographic Factors and the Distribution of Income: Some Issues." In Economic and Demographic Change: Issues for the 1980's. Liege: Internat. Union Sci. Study Population, 1979.

$\rightarrow$ Working, Holbrook. "Statistical Laws of Family Expenditure." J. American Statis. Assoc. 38 (March 1943): 43-56. 